\title{
Distinct Pattern of Neuro radiological Manifestation in Posterior Reversible Encephalopathy Syndrome
}

\author{
Mohamed ElSayed Abdelhady' ${ }^{*}$, Nida Fatima ${ }^{2 *}$, Yaman Al Kailani ${ }^{1}$, Ahmed Own', Surjith Vattoth' \\ 'Department of Neuro radiology, Hamad General Hospital, Doha, Qatar \\ 2Department of Neurosurgery, Hamad General Hospital, Doha, Qatar
}

\section{Article Info}

\section{Article Notes}

Received: November 8, 2019

Accepted: January 28, 2020

\section{${ }^{*}$ Correspondence:}

Dr. Nida Fatima, Department of Neurosurgery, Hamad General Hospital, Doha, Qatar; Email: fnida99@yahoo.com.

(c) 2020 Fatima N. This article is distributed under the terms of the Creative Commons Attribution 4.0 International License

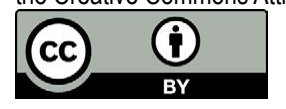

\section{Case Report}

We report a 28 years-old Female G1P0 at 35 weeks presented with headache, right sided weakness and facial deviation for 2 days. On Examination: Blood Pressure was $210 / 105 \mathrm{mmHg}$, with NIHSS score of 5 and right sided hemiparesis. CT scan Head was done which showed bilateral Gangliocapsular hypodensities with large left Gangliocapsular bleed showing intraventricular extensions along with bilateral parietooccipital predominantly subcortical subtle hypo densities, suggestive of PRES which were further confirmed by MRI findings. Brain MRI showed bilateral occipital, parietal, frontal cortex and subcortical white

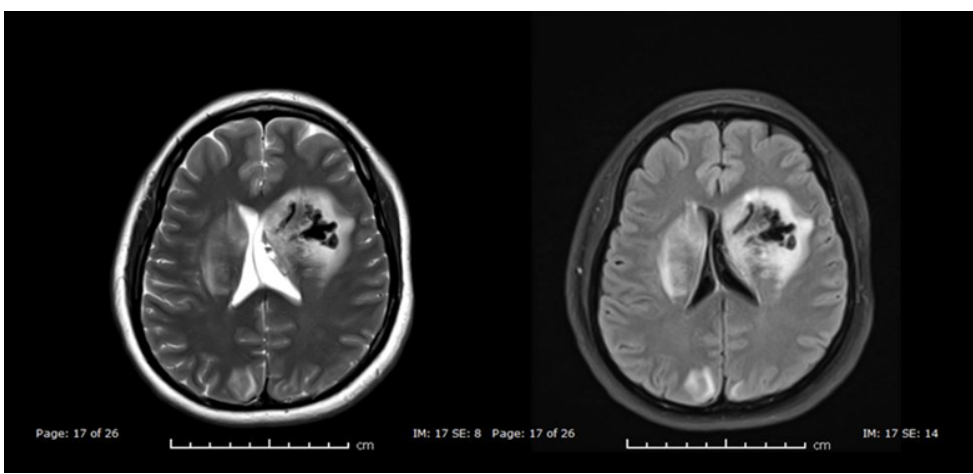

Figure 1: CT scan Head Axial Images: show bilateral gangliocapsular nearly symmetric hypodensities with large left gangliocapsular bleed showing intraventricular extension

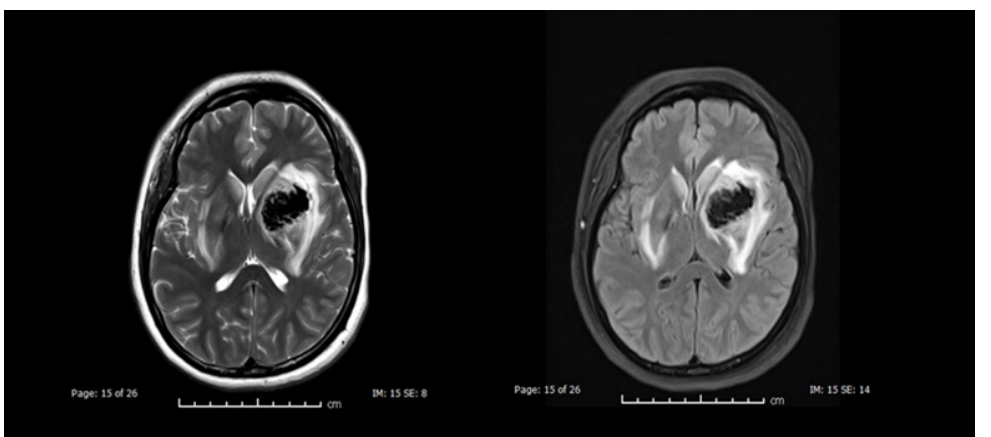

Figure 2: MRI Head Axial Images 1: T2WI (left) and FLAIR (right) show abnormal hyperintense T2/FLAIR signal intensity involving bilateral basal ganglia, internal capsules and lateral aspect of both thalami. The large left ganglio-capsular bleed is again seen demonstrating hypointense T1WI and dark T2WI signal intensity of deoxyhemoglobin (acute bleed). 


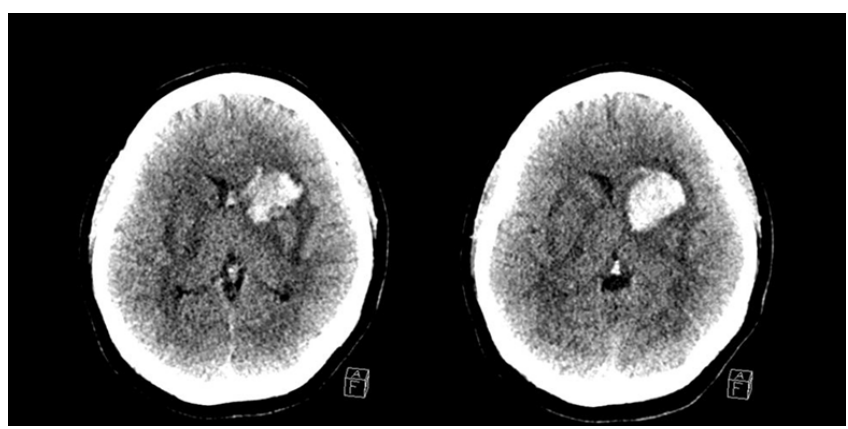

Figure 3: MRI Head Axial Images 2: Images at a higher level show bilateral parieto-occipital predominantly subcortical T2/FLAIR hyperintense signal extending to cortex; right side affected more than left.

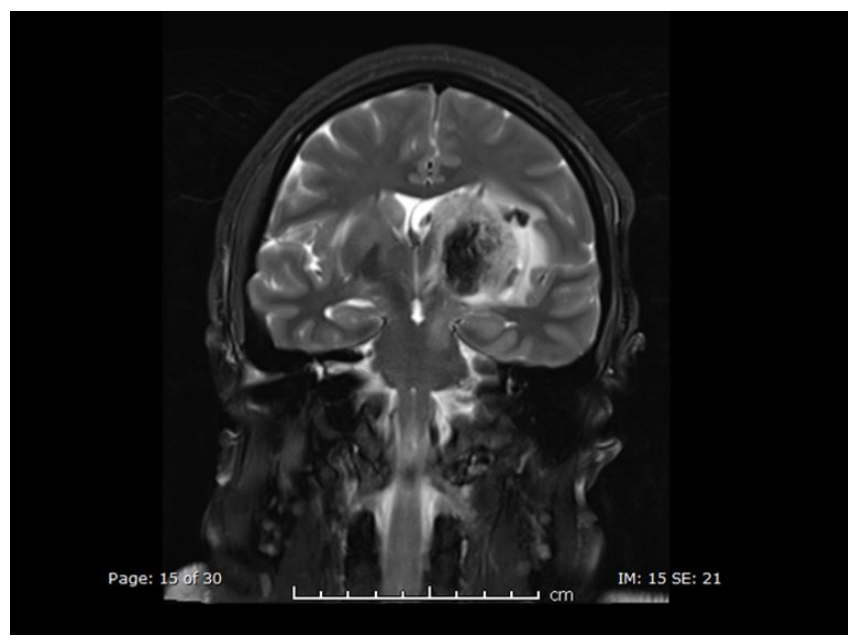

Figure 4: MRI Head Coronal Image 3: T2 Fat Sat showing extension of the signal abnormality to involve the left side of the mid brain and the pons.

matter T2/fluid-attenuated inversion recovery (FLAIR) hyperintensities, suggestive of PRES.

The blood pressure was uncontrolled even after anti-hypertensive medications; therefore, immediate Caesarian Section was performed. Patient improved after management with C/Section, IV fluids, antiepileptics and monitoring of blood pressure. If recognized and treated early, the clinical syndrome commonly resolves within a week. High index of suspicion and prompt treatment can reduce the morbidity and mortality and pave the path for early recovery.

With sudden development of headache and bilateral vision loss with elevated blood pressure, an initial diagnosis of ischemic stroke, cerebral hemorrhage and cerebral venous thrombosis, PRES and hypertensive emergency with retinal hemorrhage. A normal fundus examination essentially ruled out retinal hemorrhage, while the reversibility of symptoms with characteristic MRI findings led us to a diagnosis of PRES.

PRES is a reversible neurological entity characterized by the presence of white matter edema affecting the occipital and parietal lobes ${ }^{1,2}$. The exact incidence of PRES is unknown. Patients with renal transplantation undergoing calcineurin inhibitor therapy develop PRES syndrome in about $4-8 \%$ of the cases ${ }^{1,2,3}$. It can occur at any age and most commonly affects females. This probably reflects the fact that one of the common causes of PRES is pre-eclampsia/ eclampsia developing during pregnancy ${ }^{4}$. Pre-eclampsia and eclampsia are common medical disorders affecting pregnancy with significant maternal and fetal morbidity and mortality. Hypertension and proteinuria are hallmarks for the diagnosis of pre-eclampsia, whereas seizures are typical of eclampsia. Pre-eclampsia/eclampsia usually occurs between 20 weeks of pregnancy to $48 \mathrm{~h}$ postpartum. The term late post-partum eclampsia (PPE) is used when eclamptic events occur between $48 \mathrm{~h}$ and 4 weeks after pregnancy. A large observational study suggested that late PPE involves about $14 \%$ of cases of eclampsia ${ }^{5,6,7}$.

\section{References}

1. Bartynski WS. Posterior reversible encephalopathy syndrome, part 1: fundamental imaging and clinical features.AJNR Am J Neuroradiol2008;29:1036-42.

2. Bartynski WS. Posterior reversible encephalopathy syndrome, part 2: controversiessurrounding pathophysiology of vasogenic edema.AJNR Am J Neuroradiol2008;29:1043-9.

3. Servillo G, Bifulco F, De Robertis E,et al. Posterior reversible encephalopathysyndrome in intensive care medicine.Intensive Care Med2007;33:230-6.

4. Roth C, Ferbert A. Posterior reversible encephalopathy syndrome: long-termfollow-up.J Neurol Neurosurg Psychiatry2010;81:773-7.

5. Ishikura $\mathrm{K}$, Ikeda $\mathrm{M}$, Hamasaki Y,et al. Posterior reversible encephalopathysyndrome in children: its high prevalence and more extensive imagingfindings.AmJ Kidney Dis2006;48:231-8.

6. Rosser ML, Katz NT. Preeclampsia: an obstetrician's perspective.Adv Chronic KidneyDis2013;20:287-96

7. Matthys LA, Coppage KH, Lambers DS,et al. Delayed postpartum preeclampsia: anexperience of 151 cases.Am J Obstet Gynecology2004;190:1464-6 